\title{
Digital Concrete: Opportunities and Challenges
}

\author{
Timothy Wangler ${ }^{a *}$, Ena Lloret ${ }^{b}$, Lex Reiter ${ }^{a}$, Norman Hack ${ }^{b}$, Fabio Gramazio ${ }^{b}$, Matthias Kohler ${ }^{b}$, \\ Mathias Bernhard ${ }^{b}$, Benjamin Dillenburger ${ }^{b}$, Jonas Buchli ${ }^{c}$, Nicolas Roussel ${ }^{d}$, Robert Flatt ${ }^{a}$ \\ ${ }^{a}$ Institute for Building Materials (IfB), ETH Zurich, Switzerland \\ ${ }^{b}$ Institute for Technology in Architecture, ETH Zurich, Switzerland \\ ${ }^{c}$ Institute of Robotics and Intelligent Systems, ETH Zurich, Switzerland \\ ${ }^{d}$ Laboratoire Navier, IFSTTAR, Université Paris Est, France
}

\begin{abstract}
Digital fabrication has been termed the "third industrial revolution" in recent years, and promises to revolutionize the construction industry with the potential of freeform architecture, less material waste, reduced construction costs, and increased worker safety. Digital fabrication techniques and cementitious materials have only intersected in a significant way within recent years. In this letter, we review the methods of digital fabrication with concrete, including 3D printing, under the encompassing term "digital concrete", identifying major challenges for concrete technology within this field. We additionally provide an analysis of layered extrusion, the most popular digital fabrication technique in concrete technology, identifying the importance of hydration control in its implementation.
\end{abstract}

Keywords: Concrete; Digital Fabrication; Rheology; Set on Demand; Thixotropy

\section{Introduction}

Concrete is the most widely used material in the world, after water, with usage of about 2 billion tonnes per year. A primary reason for its popularity as a building material stems from the fact that it goes naturally from a fluid to a solid state - being able to flow and fill a mold, and upon hardening sustain a load. This gives great flexibility in terms of material handling and placement, something that has yet to be fully exploited in the world of digital fabrication.

Digital fabrication can be defined as the application of digital modeling and technologies to the production of custom material objects, and promises to revolutionize all manufacturing, having been proclaimed in recent years as the "third industrial revolution" [1]. This includes 3D printing, a subset of digital fabrication, and a technology that is still in the nascent stages of realization in the fields of architecture and construction, notwithstanding the growing attention in recent years [2-6].

In general, 3D printing has been successful with polymeric materials extruded in a liquid state and subsequently hardened, so the application of the technique to concrete, a material that undergoes a similar phase transition, seems natural, although there are some limitations with upscaling.
The enormous potential of the nexus of concrete and digital fabrication is not limited only to 3D printing, however. Other digital fabrication techniques, to be discussed in this letter, can also be implemented with concrete and overcome certain limitations with respect to 3D printing. Irrespective of this, the primary advantages of digital fabrication - freeform architecture and precision material placement - can be combined with the additional advantages of increased construction speed, reduced costs for labor and formwork, and increased worker safety. Additionally, digital fabrication is expected to lead to more sustainable construction due to more efficient structural design by placing material only where it is needed, as well as reduced waste generation due to more efficient construction techniques, especially with respect to formwork.

With this in mind, major challenges have emerged in the use of reinforced concrete in the manufacture of digitally fabricated structures, and are listed here:

- Material delivery and placement

- Control and measurement of phase transition

- Layering of material and the formation of "cold joints"

- Implementation of reinforcement or flow-induced fiber orientation

- Surface finish

* Corresponding author: Timothy Wangler, Institute for Building Materials, ETH Zurich, wangler@ifb.baug.ethz.ch 
In the following sections of this letter, these specific challenges will be addressed in the context of the varying digital fabrication technologies with concrete that have been developed to this point in time, with the major advantages and limitations of each summarized in Table 1 . These technologies can be roughly divided into two general areas: form filling, and additive manufacturing. Additionally, it is worth defining the different printing processes: binder jetting, in which binder is injected into a bed of aggregate, extrusion based printing, in which material is horizontally extruded layer by layer, and slipforming, in which material is slipped from a formwork vertically.

\section{Technologies and challenges in digital concrete}

\subsection{Form filling: custom single use formworks}

The production of digitally designed and manufactured formworks has been a major application of digital fabrication and concrete. Computer aided manufacturing (CAM) has enabled the construction of formworks of very high complexity, requiring, however, custom made formwork inlays that are generally fabricated using a computernumerical-controlled (CNC) mill to carve material out of expanded polystyrene foam (EPS) or wood. One example, pictured in Fig. 1, is the Spencer Dock Bridge in Dublin from Amanda Levete Architects [7]. This bridge, constructed in 2012, required more than 100 formwork inlays to be custom milled for a single use. Other examples abound, such as the 0-14 Tower by Reiser \& Umemoto, constructed in Dubai in 2012, where CNC cut formwork inlays were used for the production of a unique structural façade with 1300 uniquely shaped openings [8]. In spite of the geometrical possibilities, CNC milling is considered unsustainable due to the single use of the formwork and the slow, energy intensive production process [9]. While layering of material is not a major issue, custom reinforcement must be manufactured and installed. Despite its drawbacks, CNC milling of custom formworks remains one of the most efficient techniques to date for producing concrete structures with non-standard geometries.

\subsection{Form filling: Stay-in-place formworks}

An alternative to the subtractive process of CNC milling is to digitally fabricate a stay-in-place formwork. This strategy can be more sustainable considering the inefficiencies inherent to subtractive processing, and the digitally fabricated formworks can have additional uses beyond that of merely formwork. An example is the Mesh Mould Metal process seen in Fig. 2, developed at ETH Zurich, in which an industrial robot with a customized end effector bends and welds metal wires into a 3D mesh structure, which acts as a porous formwork during the concreting process and serves as reinforcement upon setting [11-14]. Surface finishes can be effected robotically or manually. This process addresses the challenges that layer-based concrete printing processes are facing, namely the integration of reinforcement, and the formation of distinct layers, or "cold joints", due to inadequate layer intermixing. Due to the dexterity and versatility of the robot, complex mesh geometries can be fabricated without increasing costs, and a major advantage of this process is its application on site, where a mobile robot can produce these meshes in situ.

Alternatively, production of stay-in-place formworks can be done in a prefabrication setting, as in the case of recent developments in the use of 3D sand printing to produce nonstandard complex concrete elements.
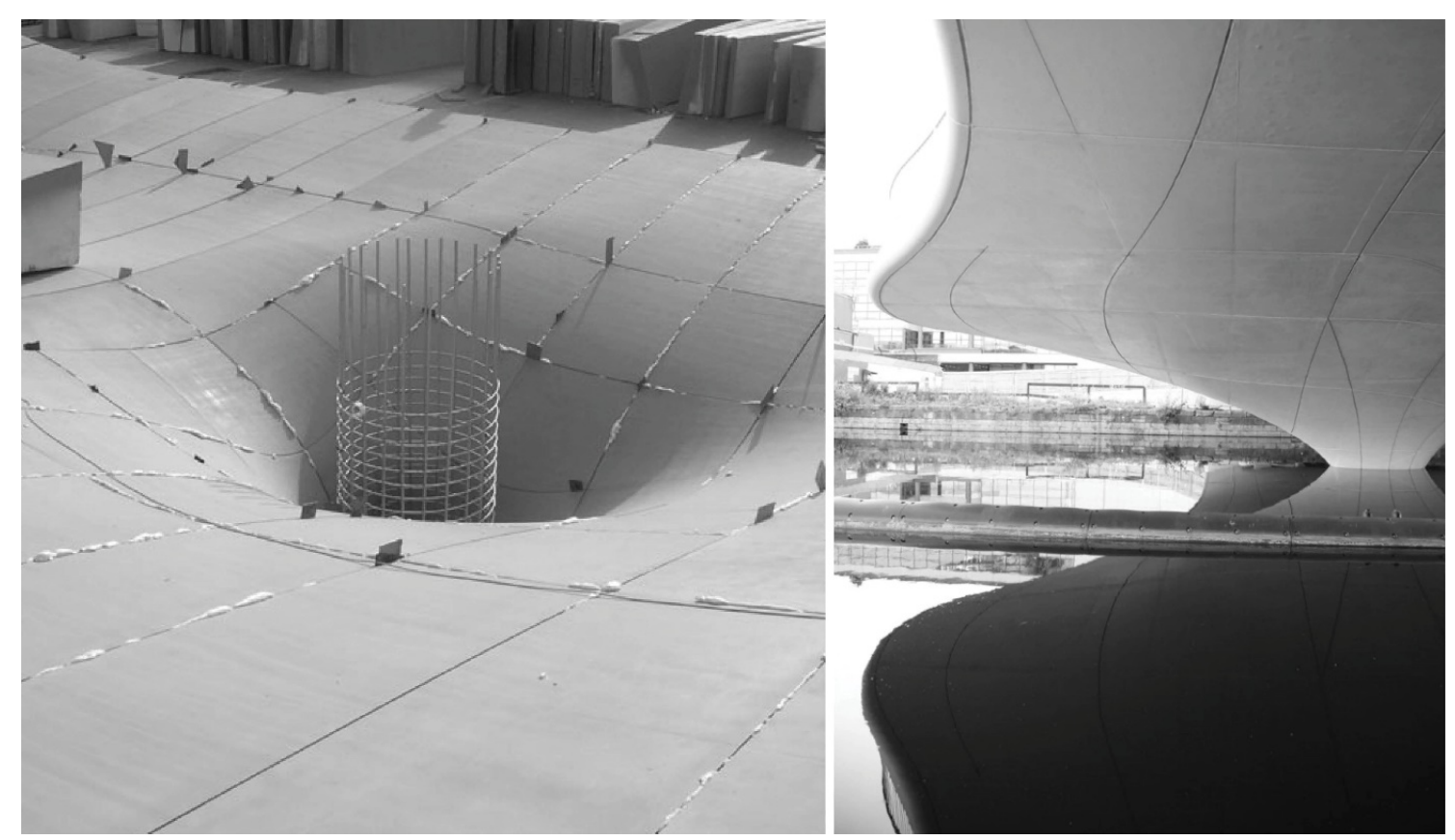

Figure 1. (Left) Finalized CNC milled and assembled formwork for casting. (Right) View under the Spencer Dock Bridge by Amanda Levete Architects, Dublin, 2012 [10]. 


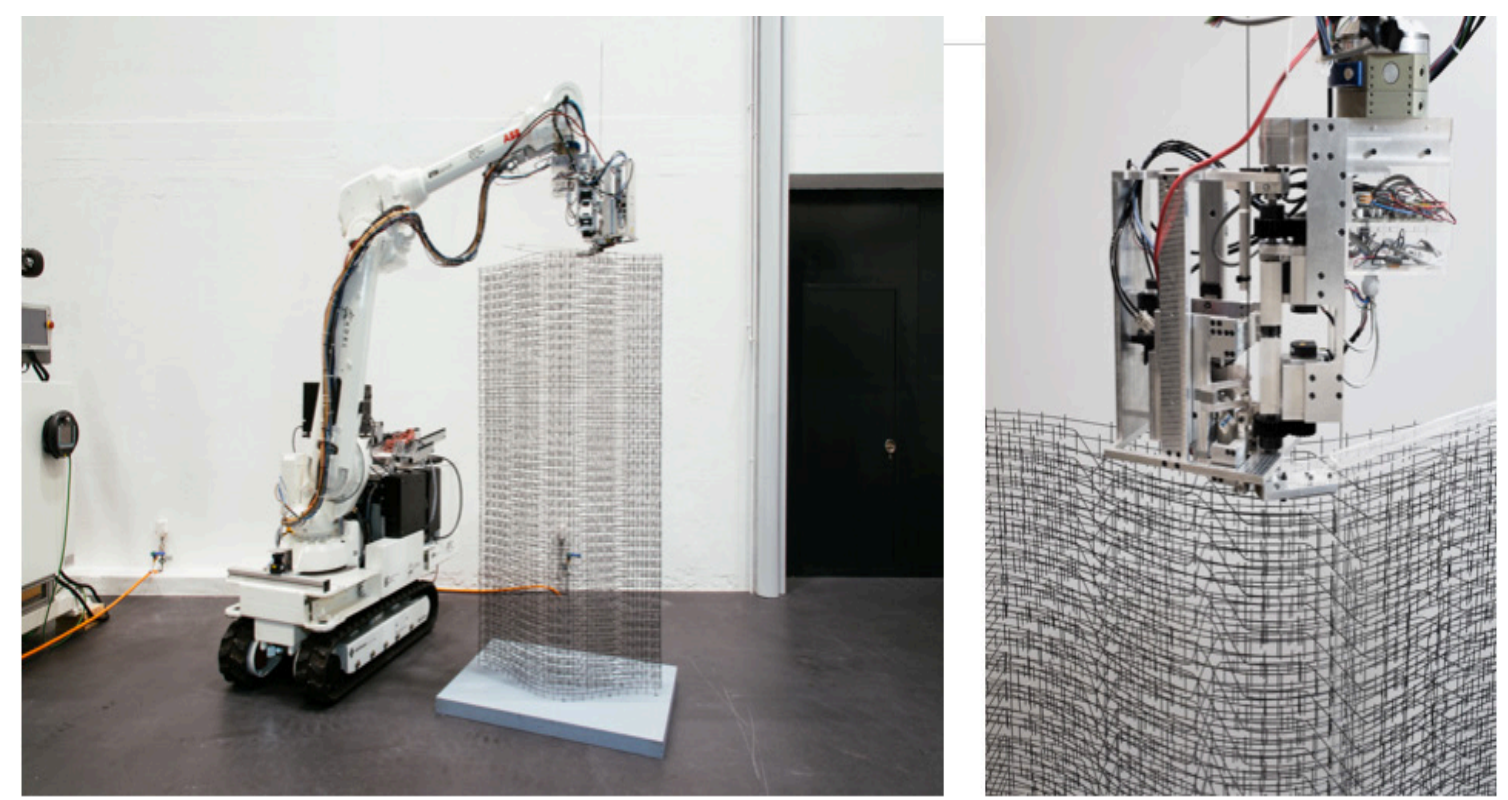

Figure 2. (Left) Mesh Mould produced with the In Situ Fabricator robot from ETH Zurich dfab. (Right) Close up of In Situ Fabricator tool head.

This process is a binder jetting process, where a print head deposits a liquid binder on a loose powder bed to bond the part layer by layer. Both inorganic and organic binders exist. To date, this process has been used primarily for the production of casting molds for metal parts, but recently is being investigated as a method to produce architectural elements with resolutions on the order of millimeters [15, 16]. This process can take full advantage of the almost unrestricted geometric freedom of a binder jetting printing process and combine it with the structural capabilities of concrete, by printing elements that can subsequently be assembled and infilled with a structural concrete. Intricate branching topologies that allow for the reduction of concrete used can be designed, as well as inner structures that allow integration of additional systems. While this process has the limitation of all 3D printing processes, in which the element size is limited by the size of the printer, the most complex details designed into the elements do not lead to an increase in production time or cost, making it a competitive candidate for creation of formwork. Reinforcement remains a challenge with this technology, although steel fiber reinforced concrete can be infilled, or channels to allow reinforcement through post tensioning can be printed. Indeed, digital concrete can open an entirely new area of application for steel fiber reinforced concrete and another benefit to study flow-induced fiber orientation, due to the potentially unlimited geometrical possibilities of this technology.

\subsection{Additive Manufacturing: Binder Jetting}

In contrast to infilling either single use or stay-in-place formworks, additive manufacturing with concrete can be performed. The binder jetting process described earlier in the production of 3D printed sand molds can be applied to print concrete elements directly, either by using cement in the powder bed and injecting water or other liquid as binder, or by injecting cement paste into an aggregate bed. This has been under investigation for use in construction for a couple of decades [17], but only recently this process has been used to produce complex elements by architect Enrico Dini, as well as the California-based firm Emerging Objects [18, 19]. Compared to other $3 \mathrm{D}$ printing methods for architectural applications, binder jetting allows for a high degree of geometric freedom, as stated earlier, even allowing cantilevered or hollow parts because the unbound powder supports the part during fabrication. While parts with the structural capacity of unreinforced Portland cement can be printed [20], again the introduction of reinforcement remains problematic. The layer height is restricted by the binding process, and determines both speed and the level of detail, and recycling of unbound cement powder may be problematic with exposure to humidity. Additionally, postmanufacture processing is often necessary, such as infiltration of epoxy or additional curing steps. The future challenge for binder jetting will be to broaden the spectrum of printable powder-binder combinations to increase the stability of the printed parts - including reinforcement - and to reach a more environmentally friendly and sustainable fabrication.

\subsection{Additive Manufacturing: 3D Printing by layered extrusion}

Layered extrusion 3D printing is the typical process that comes to mind when the term 3D printing is invoked, based on its widespread use in the production of custom parts out of various polymers. This technique, in which a digitally controlled nozzle precisely extrudes concrete layer by layer, has been researched extensively by several research institutions and companies over the last decade. The pioneer of concrete 3D printing is Prof. Khoshnevis from the University of Southern California, who developed a process called Contour Crafting as early as 2004 [2, 3, 5], with the aim of printing high-rise buildings and even houses on the moon [21]. A similar approach is being taken by the Free 
Form Construction research project at Loughborough University since 2010 [4, 5, 22]. Independent of scale, 3D printing requires a modular, transportable printer that must be as large as the structure being produced. In both processes, the layers are generally on the order of a few centimeters, and the formation of cold joints remains an open question. The incorporation of reinforcement is difficult, as steel rebar must not impede the movement of the printer head. This issue is addressed by printing hollow structures to place rebar afterward, with infilled concrete making the connection to the printed structure. This renders the process as essentially a stay-in-place formwork production process.
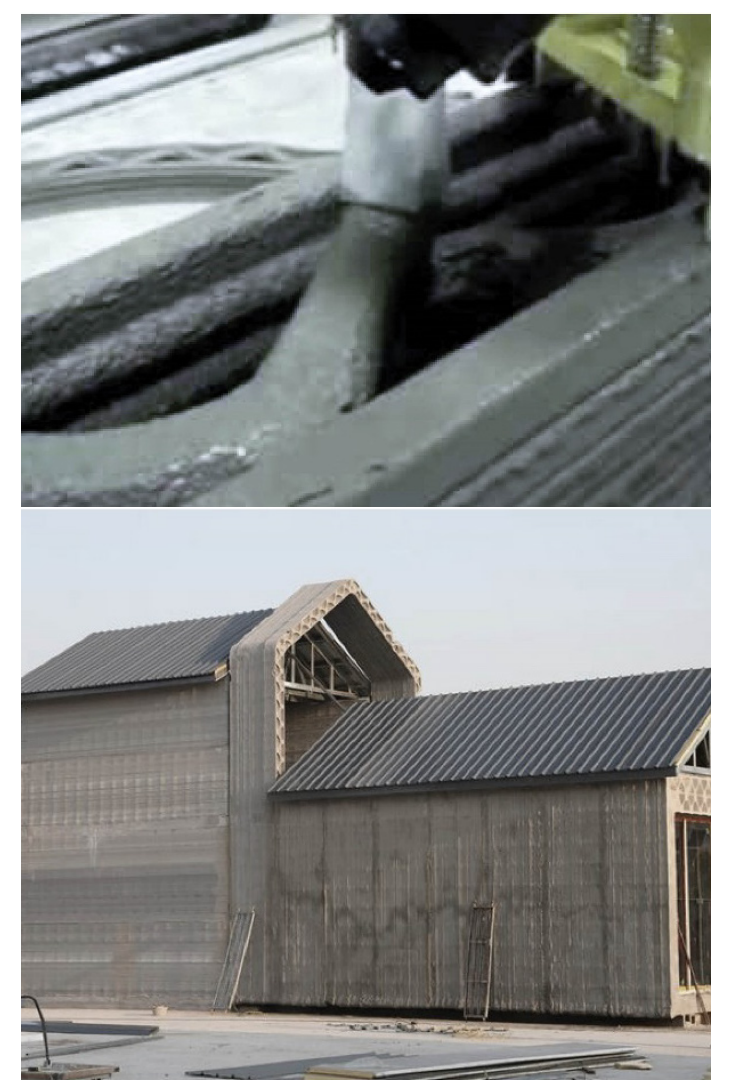

Figure 3. (Top) Contour Crafting, with layers of approximately $5 \mathrm{~cm}$. (Bottom) House printed and assembled by WinSun.

These two pioneering projects have rapidly affected the growing field of 3D printing with concrete, resulting in several research institutions and companies exploring the prefabrication of architectural elements. One example is the company WinSun in Shanghai, who recently succeeded in printing full scale houses in less than $24 \mathrm{~h}$ by prefabricating and assembling various portions of the structure (Fig. 3) [23]. Other examples include the company Total Kustom from architect Andrey Rudenko, who recently produced a 3D printed hotel suite in the Philippines [24], and the project WASP, which launched the world's biggest 3D printer, a 12 $\mathrm{m}$ tall hexagonal shaped structure [25]. The Chinese company HuaShang Tengda has recently 3D printed a $400 \mathrm{~m}^{2}$ villa around reinforcement through the use of a novel nozzle design, seemingly eliminating one of the major challenges of 3D printing concrete using horizontal extrusion based technology [26]. Burgeoning research interest has led to the establishment of materials-based approaches in recently launched projects such as ConPrint3D at TU Dresden and 3D Concrete Printing at TU Eindhoven, as well as the XTreeE team in France [27-29].

One of the greatest challenges with $3 D$ printing with concrete has to do with vertical building rate. The concrete must be soft enough to be extruded and to intermix with the previously deposited layer, but must support its own weight and the weight of the material to be subsequently deposited. However, formation of a cold joint should be avoided, meaning there is a finite "waiting time" between layers. This topic is addressed directly later in this letter with respect to production, but the importance of cold joints as they impact final material structural performance and durability remains an open research area. This is in addition to the obvious impact that layering has on the surface finish.

\subsection{Additive Manufacturing: Slipforming}

In contrast to layered extrusion 3D printing, a process known as Smart Dynamic Casting (SDC), developed at ETH Zurich in 2012, scales down the well-known construction technique of vertical slipforming to produce non-standard concrete elements robotically [30,31]. While traditional slipforming is useful in producing elements on the order of several $\mathrm{m}^{2}$ in cross section, SDC produces elements on the order of $\mathrm{cm}^{2}$ in cross section by robotically moving a defined formwork significantly smaller than the element produced. In both processes, concrete enters a hollow formwork in the fluid state, and exits in a hardening state, meaning that control of hydration is essential. At the scale of traditional slipforming, this is achieved by controlled delivery and placement of large batches with time, but in the case of SDC, hydration control is performed via chemical admixtures. A large batch of heavily retarded self-compacting concrete is pumped and activated by increments using accelerators [32, 33], enabling a vertical building rate on the order of $1 \mathrm{~m} / \mathrm{h}$. The process is schematically shown in Fig. 4.

Feedback process control is necessary, as the material that exits the formwork must be able to support the material above it, but cannot remain in the formwork for too long, as friction between the material and the formwork can lead to cracking [34, 35].

With SDC, one can envision a whole array of vertical elements that can be produced with a single formwork concept, and a major advantage the process has is that implementation of reinforcement is possible during production. Additionally, the continuous nature of the process eliminates layering and cold joint formation. The formwork type will, however, constrain the geometric possibilities of SDC, meaning that formwork design is essential to the overall process. 
A

C

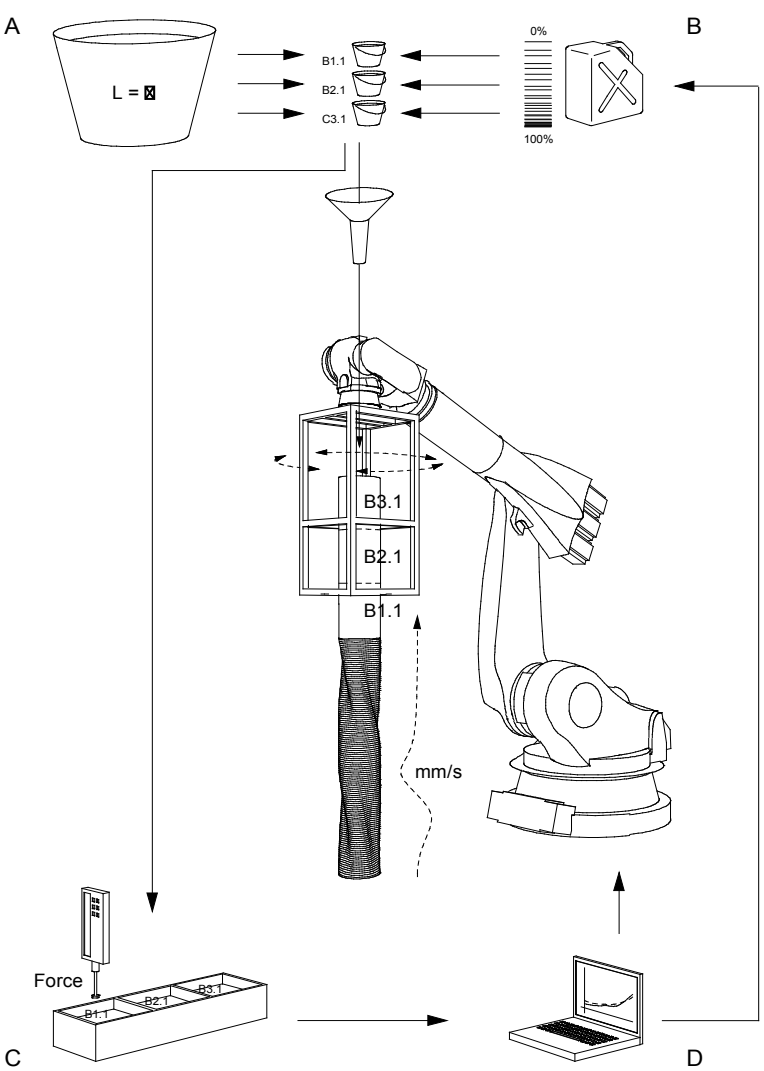

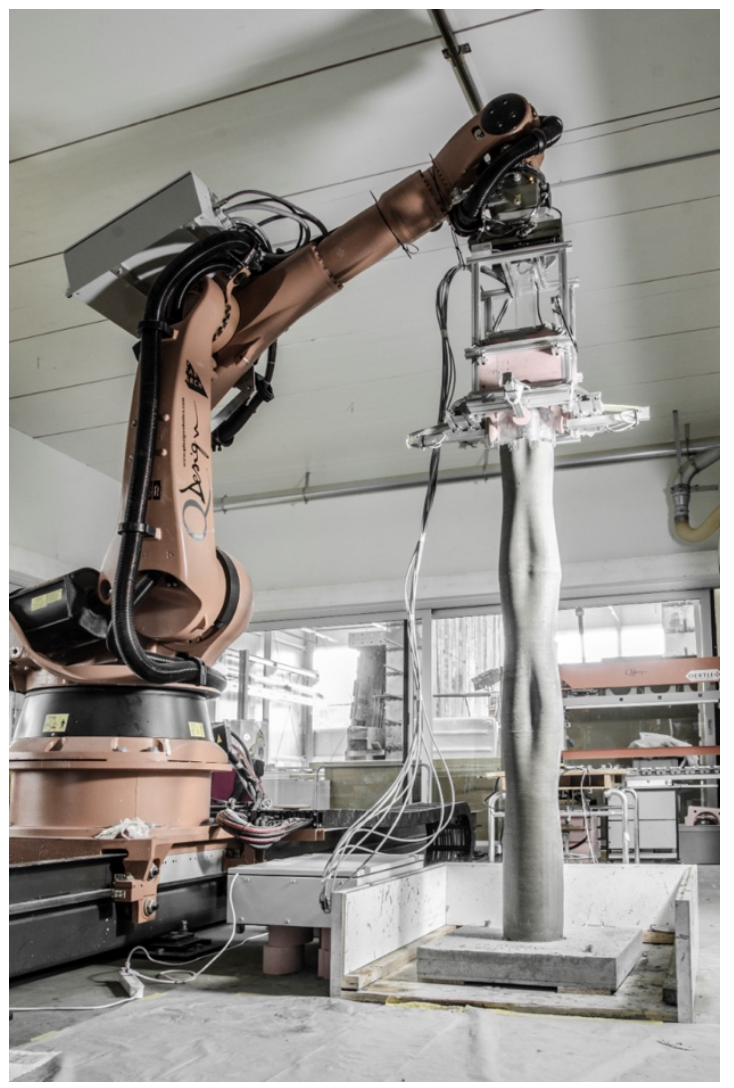

Figure 4. (Left)A- Retarded material. B - Chemical admixtures for accelerations. C - Inline measurement system. D - Algorithmic tool and robotic control [31]. (Right) column prototype $\sim 2 \mathrm{~m}$ in height produced with alternating indentation and straight trajectory.

Table 1: Summary of major digital concrete technologies to date.

\begin{tabular}{|c|c|c|c|c|c|c|}
\hline \multirow[b]{2}{*}{ Technology } & \multicolumn{3}{|l|}{ Mould Production } & \multirow{2}{*}{ Layered Extrusion } & \multirow{2}{*}{ Binder Jetting } & \multirow{2}{*}{ Slipforming } \\
\hline & CNC Milling & Binder Jetting & Steel Welding & & & \\
\hline \multirow[b]{2}{*}{ Examples } & \multirow[b]{2}{*}{ numerous } & \multirow[b]{2}{*}{ ETH Zurich dbt } & \multirow{2}{*}{$\begin{array}{l}\text { Mesh Mould } \\
\text { Metal }\end{array}$} & Contour Crafting & \multirow[b]{2}{*}{ D-Shape } & \multirow[b]{2}{*}{$\begin{array}{l}\text { Smart Dynamic } \\
\text { Casting }\end{array}$} \\
\hline & & & & $\begin{array}{l}\text { Freeform } \\
\text { Construction }\end{array}$ & & \\
\hline \multirow[b]{3}{*}{ Advantages } & \multicolumn{2}{|l|}{ High resolution } & Reinforcement & Shape freedom & High resolution & Reinforcement \\
\hline & \multicolumn{2}{|l|}{ High surface quality } & \multirow[t]{2}{*}{ On site potential } & On site potential & Cantilevering & \multirow{2}{*}{$\begin{array}{l}\text { Surface quality } \\
\text { Smooth interfaces }\end{array}$} \\
\hline & & Stay-in-place & & & & \\
\hline \multirow{4}{*}{$\begin{array}{l}\text { Limitations \& } \\
\text { Challenges }\end{array}$} & Single use & $\begin{array}{l}\text { Unbound powder } \\
\text { removal }\end{array}$ & $\begin{array}{l}\text { Concrete } \\
\text { placement }\end{array}$ & Reinforcement & Reinforcement & $\begin{array}{l}\text { Limited shape } \\
\text { freedom }\end{array}$ \\
\hline & \multicolumn{2}{|l|}{ Reinforcement } & & Cold joints & $\begin{array}{l}\text { Unbound powder } \\
\text { removal }\end{array}$ & Prefab only \\
\hline & & $\begin{array}{l}\text { Formwork } \\
\text { pressure }\end{array}$ & & $\begin{array}{l}\text { Formwork } \\
\text { pressure }\end{array}$ & $\begin{array}{l}\text { Unbound powder } \\
\text { recycling }\end{array}$ & \\
\hline & & & & $\begin{array}{l}\text { Layered surface } \\
\text { finish }\end{array}$ & & \\
\hline
\end{tabular}

\section{Materials Science Insight into the Main Challenges}

As most research activity in digital fabrication is focused on layered extrusion technology such as Contour Crafting, the following analysis offers insight into what we perceive is a major challenge in this technology and indeed in all layer based additive manufacturing technologies: the need to have deposited material sustain its own weight and the weight of subsequent layers while simultaneously intermixing enough to avoid a cold joint.

\subsection{Yield stress change from layer to structure}

In layered extrusion of concrete, a cementitious material is extruded and objects are built up layer by layer, as depicted schematically in Fig. 5. After extrusion, the initial yield stress of any layer, $\tau_{0,0}$, must support itself so [36]:

$\tau_{0,0}=\rho g h / \sqrt{3}$

where $\rho, g$ and $h$ are the density, gravity constant and layer height. 
At the end of the process, the yield stress of the lowest layer, $\tau_{0, f}$, must be sufficient to carry the entire height $H_{m}$ :

$\tau_{0, f}=\rho g H_{m} / \sqrt{3}$

So the ratio of initial and final yield stresses is:

$\tau_{0, f} / \tau_{0, i}=H_{m} / h$

To the best of our knowledge, layer thicknesses are of the order of 1-3 cm, while final heights are between $80-150 \mathrm{~cm}$. Therefore, $\tau_{0, f} / \tau_{0, i}$ varies between 25 and 150 .

Yield stress can be written as a product between a function of volume fraction and an average interparticle force [37]. If we neglect hydration, then $\tau_{0, f} / \tau_{0, i}$ gives the ratio of interparticle forces, which, in turn, can be related to thicknesses of effective steric hindrance layers, $\delta$ [38]:

$\delta_{i} / \delta_{f}=\sqrt{\tau_{0, f} / \tau_{0, i}}$

This ratio would vary between 5 and 12 . In the simplest case $\delta_{f}$ is the average solvent layer in absence of admixtures, estimated as $0.8 \mathrm{~nm}$ [39]. Therefore, the initial layer thickness would have to vary between 4 and $10 \mathrm{~nm}$.

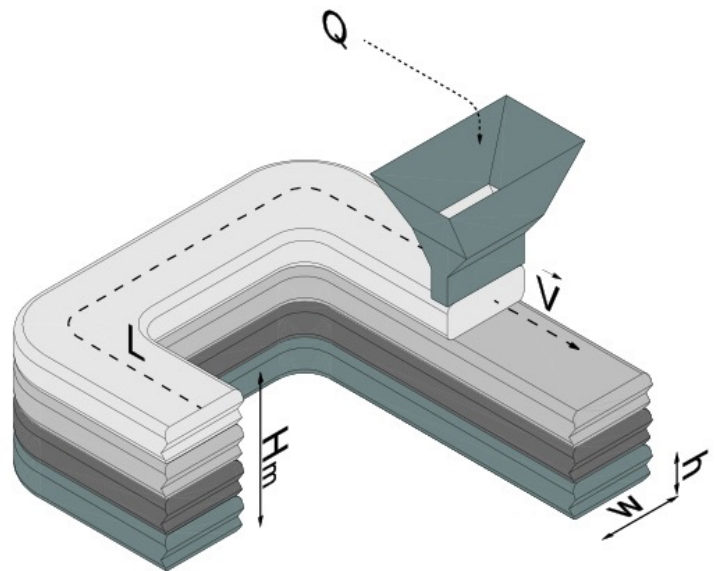

Figure 5. Schematic of a layered extrusion process with concrete. A digitally controlled extrusion head moves at velocity $V$, creating layers of individual height $h$ and width $w$. The overall height, $\mathrm{Hm}$, is dependent on the velocity and contour length, $L$.

This is larger or much larger than what is generally obtained with superplasticizers, so we conclude that the yield stress increase and therefore the phase transition cannot come exclusively from cancelling dispersion by super-plasticizers. This leaves the following options:

1) The extruded material does not deform and has a higher initial yield stress. Apart from requiring higher extrusion pressures, this enhances the risk of forming cold joints between layers.

2) Hydration is at the origin of the yield stress increase, but must not compromise rheology upstream of the extruder.
For this, the material may be activated prior to extrusion or its yield stress build up may be countered (for some period) by continuous and intensive mixing upstream.

3) Fresh material is continuously or semi-continuously being prepared upstream.

In one form or another these situations introduce concerns about the binding of one layer to the next, which is considered next.

\subsection{Rate of thixotropic build up}

In digital fabrication, the rate at which yield stress increases is an important process parameter, which we note as $A_{\text {thix }}$ [36]. With $t_{H, \text { min }}$, the minimum time needed to reach the final layer, producing an element of height $H_{m}$, we then have:

$A_{\text {thix }}=\rho g H_{m} / \sqrt{3} t_{H \text { m,min }}=\rho g h / \sqrt{3} t_{h, \text { min }}$

where $t_{h, \min }$ is the time minimum for producing a layer. For purely thixotropic processes (i.e. reversible flocculation), an upper bound for $A_{\text {thix }}$ is $2 \mathrm{~Pa} / \mathrm{s}$ [40], so the shortest time to produce $1 \mathrm{~m}$ high object cannot be less than $1 \mathrm{~h} 40$ minutes if one purely relies on thixotropy.

For what follows it is also useful to express $t_{h, \min }$ as a function of $A_{\text {thix }}$ :

$t_{h, \min }=\rho g h /\left(\sqrt{3} A_{\text {thix }}\right)$

This can be used to define a maximum horizontal velocity $V$, above which structural build up would not be fast enough to support the rate of material deposition:

$V<\sqrt{3} L A_{\text {thix }} /(\rho g h)$

where $L$ is the contour length. For contour crafting wall geometries, based on observations of the typical wall production process, this would be about 3 times larger than element length, $L_{E}$.

\subsection{Cold joints}

Cold joints arise between successively cast layers of concrete that have limited intermixing. It can occur if a critical resting time is exceeded [40], defining a maximum time for a layer to be produced (Fig. 6):

$t_{h, \text { max }}=\frac{\sqrt{\frac{(\rho g h)^{2}}{12}+\left(\frac{2 \mu_{P} V}{h}\right)^{2}}}{A_{\text {thix }}}$

where $\mu_{P}$ is the plastic viscosity. In (8), the role of yield stress has been dropped from the original analysis, which for selfcompacting concrete is generally a reasonable assumption. For contour crafting, the higher yield stress of the two layers ought to imply that equation (8) provides an upper bound of the critical resting time. Clearly, a more detailed analysis would be noted to clarify this situation. However, at this stage, we can note that the freshly extruded layer should have a yield stress of half or less than the underlying layer 
and that consequently equation (8) may provide reasonable approximations.

This must be larger than the layer production time, so to avoid cold joints, therefore also larger than the shortest possible layer extrusion time given in (6). It implies that the linear production velocity must be larger than:

$$
V>\frac{\rho g h^{2}}{4 \mu_{P}}
$$

\subsection{Operation window}

Equations (6) and (8) define an operation window in terms of time to produce a layer (Fig. 6), while equations (7) and (9) do this in terms of horizontal velocity. The latter can be used to define a minimum contour length as:

$L>\frac{\sqrt{2 / 3}}{8} \frac{(\rho g)^{2} h^{3}}{A_{\text {thix }} \mu_{P}}$

For a layer thickness of $1-3 \mathrm{~cm}$, plastic viscosity of $50 \mathrm{~Pa} \cdot \mathrm{S}$, a density of $2400 \mathrm{~kg} / \mathrm{m}^{3}$ and a yield stress increase rate of $2 \mathrm{~Pa} \cdot \mathrm{s}$, the crafted length would have to be at least 0.6 and $15 \mathrm{~m}$. Otherwise, a dead time must be introduced between each layer to avoid collapse. If the rate of yield stress buildup is rather on the low side ( $0.1 \mathrm{~Pa} \cdot \mathrm{S})$, then the minimum crafted lengths shift to 11 and $300 \mathrm{~m}$. Under those conditions the linear velocity remain low in comparison to what can be expected $(0.2 \mathrm{~m} / \mathrm{s})$.

\subsection{Summary and outlook}

This analysis shows that, for continuous layer-by-layer deposition of concrete, an operation window can be defined with maximum and minimum horizontal velocities. They define the relationships allowing yield stress to build up enough to hold up the next layer and to avoiding the formation of cold joints. This defines minimum horizontal lengths, which depend on layer thickness, rate of yield stress build-up, plastic viscosity and density. Fig. 6 gives a view of how structural build up affects the vertical build rate.

The existence of these critical lengths poses a problem for producing slender objects, which is why hydration activators are used in such cases, such as in Smart Dynamic Casting which has been described earlier [31], and more recently has been applied in the process developed by XTreeE in the past year [29]. More generally, it poses a challenge for upscaling since material properties and process parameters are interlinked. More specifically, upscaling a process developed on a (too) small scale will require substantial changes to the material properties. Since getting the right material properties is the greatest challenge, the amount of effort associated will be considerable.

Finally, we identify that, for objects with a height above 1-1.5 $\mathrm{m}$, simply relying on thixotropy for structural build up will not be very effective, which is also schematically illustrated in Fig. 6. Rather, chemical reactions are needed and this raises an exciting challenge for materials chemistry. This can be defined as: "Setting on Demand", whereby a material is put to sleep and activated just before placing. Alternatively, but subject to the same fundamental requirement, fresh material can be continuously mixed and prepared upstream. In both cases, the rate at which yield stress increases is bound by process parameters through equation (10).

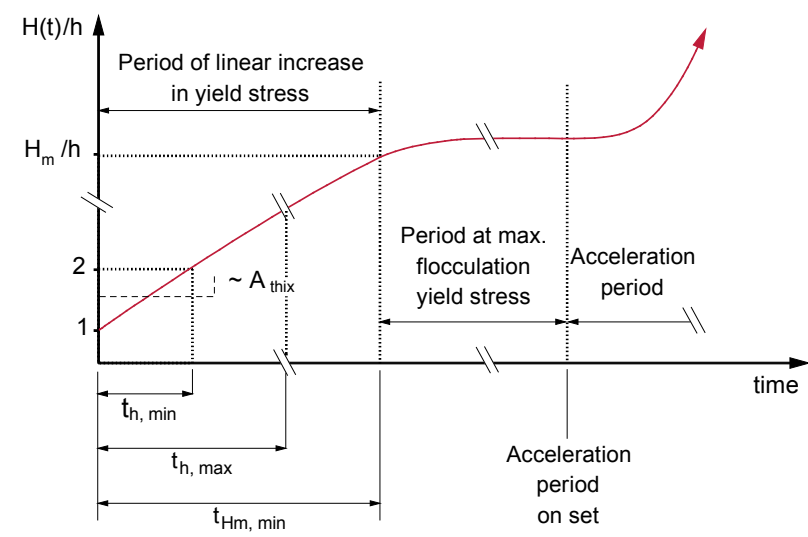

Figure 6. Element height vs. time for digital concrete processes. Initial strength correlates to a yield stress limited by flocculation processes. Hydration at beginning of acceleration process is necessary for higher element height and faster vertical building rates. The rate of thixotropic build up is given as Athix, where $A$ is normalized by the yield stress to sustain a single layer as given in (1).

\section{Challenges in Robotics in Digital Fabrication with Concrete}

Reinforced concrete is a composite material, and assembling a concrete wall with relevant performance for construction requires a complex assembly of various materials and involves a multitude of processing steps. For example, for the Mesh Mould Metal process described earlier, the basic minimal steps include material feeding, cutting, joining (e.g. welding), bending, and possibly others. Not surprisingly the mechatronic challenges involved in turning such a material system into a digital fabrication process are significant. The challenges require rethinking the material system and assembly process as a whole and through the lens of mechatronic boundary constraints rather than human assembly. These constraints come from a combination of concrete mix limitations, structural requirements, mesh topology, mechatronic toolhead, robotic setup and parametric design. Each of these aspects are mutually adjusted to the needs of the others and are critical in enabling the overall digital concrete process.

Some of the most fundamental mechatronic challenges for digital concrete are at the same time fundamental challenges in robotics and digital fabrication in architecture at large. They pertain to sensing, localization (global and relative to a workpiece) handling of unknown, partially unknown or imprecise geometries and work pieces. Desirably digital concrete would be used as an in situ process, thus questions of mobile robotics (mobility, actuation, localization) need to be addressed. 
However, some of these challenges at the same time also offer unique potential and indicate where Digital Fabrication Material systems will allow going way beyond current building paradigms. For example, the need for constant online feedback of the mechatronic device on the process generates a rich, highly informative data stream that can be subsequently stored and mined for quality assurance, compliance monitoring, informing other process steps, business optimization and so on. Solving the self-localization challenges within the built environment and against the workpiece will alleviate the need for external measurement solutions thus rendering the systems more efficient. They will allow working with inaccuracies that are inherent in the process in a pro-active and creative way.

\section{Conclusion}

Concrete, the world's most widely used manmade material, is on the cusp of a revolution as the implementation of digital technologies in the fields of construction and architecture begins to take hold in a major way. The major technologies up to this point have been recorded in this letter, with new breakthroughs expected to come out at a dizzying pace. For the concrete technologist, material placement, hydration control, and implementation of reinforcement remain major research problems, while the formation of cold joints and the impact on durability is an open question. To close, it is essential to point out the importance of interdisciplinary research. Digital fabrication with concrete will require the intense collaboration of architects, materials scientists, roboticists, and structural engineers, among others. Major advancements in digital concrete can only occur when each party brings the constraints imposed by their respective fields to the table, and a realizable solution is put forth.

\section{Acknowledgements}

Research in Digital Concrete at ETH Zurich is supported by the Swiss National Science Foundation National Centre for Competence in Research in Digital Fabrication - Innovative Building Processes in Architecture, which commenced funding in 2014. This is supporting the research in Smart Dynamic Casting, Mesh Mould Metal, and 3D sand printed UHPFRC composites.

\section{References}

[1] The third industrial revolution. The Economist (2012)

[2] B. Khoshnevis, Automated construction by contour crafting-related robotics and information technologies. Autom Constr (2004) 13: 519. http://dx.doi.org/10.1016/j.autcon.2003.08.012

[3] B. Khoshnevis, D. Hwang, K.-T. Yao, Z. Yeh, Mega-scale fabrication by Contour Crafting. Int J Ind Syst Eng (2006) 1: 301-320. http://dx.doi.org/10.1504/IJISE.2006.009791

[4] R.A. Buswell, R.C. Soar, A.G.F. Gibb, A. Thorpe, Freeform Construction: Mega-scale Rapid Manufacturing for construction. Autom Constr (2007) 16: 224-231. http://dx.doi.org/10.1016/j.autcon.2006.05.002
[5] S. Lim et al., Developments in construction-scale additive manufacturing processes. Autom Constr (2012) 21: 262-268. http://dx.doi.org/10.1016/i.autcon.2011.06.010

[6] A. Perrot, D. Rangeard, A. Pierre, Structural built-up of cementbased materials used for 3D-printing extrusion techniques. Mater Struct (2016) 49: 1213-1220. http://dx.doi.org/10.1617/s11527-015-0571-0

[7] C. Lavery, Spencer Dock Bridge. Concr Int (2013) 35: 28-31.

[8] In progress: 0-14 tower by Reiser + Umemoto. In: ArchDaily (2009) http://www.archdaily.com/22200/in-progress-0-14-tower-by-reiserumemoto/. Accessed 21 Aug 2016.

[9] L. Li, J. Yan, Z. Xing, Energy requirements evaluation of milling machines based on thermal equilibrium and empirical modelling. $J$ Clean Prod (2013) 52: 113-121. http://dx.doi.org/10.1016/j.jclepro.2013.02.039

[10] Spencer Dock Bridge Dublin - Nedcam / Modellbau Nachtigall. http://www.nedcam.com/spencer-dock-bridge-dublin.htm. Accessed 8 Sep 2016

[11] N. Hack, W.V. Lauer, Mesh-Mould: Robotically Fabricated Spatial Meshes as Reinforced Concrete Formwork. Archit Des (2014) 84: 4453. http://dx.doi.org/10.1002/ad.1753

[12] W.V.L. Norman Hack, Mesh Mould: Robotically Fabricated Metal Meshes as Concrete Formwork and Reinforcement (2015).

[13] T. Sandy, M. Giftthaler, K. Doerfler, M. Kohler, J. Buchli, Autonomous repositioning and localization of an in situ fabricator. IEEE International Conference on Robotics and Automation. (2016) 28522858. http://dx.doi.org/10.1109/icra.2016.7487449

[14] N. Kumar et al., Design, Development, and Experimental Assessment of a Robotic End-effector for Non-standard Concrete Applications. IEEE International Conference on Robotics and Automation (2017), submitted.

[15] Casting of concrete. http://www.voxeljet.de/en/case-studies/casestudies/casting-of-concrete/. Accessed 25 Aug 2016

[16] dbt, Digital Building Technologies. http://www.dbt.arch.ethz.ch Accessed 21 Aug 2016

[17] J. Pegna, Exploratory investigation of solid freeform construction. Autom Constr (1997) 5: 427-437. http://dx.doi.org/10.1016/S0926-5805(96)00166-5

[18] Bloom, Emerging Objects. http://www.emergingobjects.com/project/bloom-2/. Accessed 21 Aug 2016.

[19] D-shape. http://www.d-shape.com. Accessed 21 Aug 2016.

[20] G. Cesaretti, E. Dini, X. De Kestelier, V. Colla, L. Pambaguian, Building components for an outpost on the Lunar soil by means of a novel 3D printing technology. Acta Astronaut (2014) 93: 430-450. http://dx.doi.org/10.1016/i.actaastro.2013.07.034

[21] B. Krassenstein, Contour Crafting Inventor Dr. Khoshnevis: Widespread 3D Printed Homes in 5 Years, High-Rises in 10 Years. 3DPrint.com (2015)

[22] T.T. Le, et al., Mix design and fresh properties for high-performance printing concrete. Mater Struct (2012) 45: 1221-1232. http://dx.doi.org/10.1617/s11527-012-9828-z

[23] N. Davison, 3D-printed cities: is this the future? The Guardian (2015).

[24] Rudenko 3D Printer. http://www.totalkustom.com/. Accessed 21 Aug 2016.

[25] CONCRETE BEAM CREATED WITH 3D PRINTING - WASP. http://www.wasproject.it/w/en/concrete-beam-created-with-3dprinting/. Accessed 21 Aug 2016.

[26] Exquisite $400 \mathrm{~m}^{2}$ villa 3D printed on-site in Beijing in just 45 days. In: 3ders.org. http://www.3ders.org/articles/20160614-exquisite-400m2-villa-3d-printed-on-site-in-beijing-in-just-45-days.html. Accessed 21 Aug 2016.

[27] CONPrint3D. In: TU Dresd. https://tu-dresden.de/bu/bauingenieurwesen/ifb/dasinstitut/news/CONPrint3D?set_language=en. Accessed 11 Aug 2016

[28] 3D Concrete Printing http://www.tue.nl/universiteit/faculteiten/bouwkunde/onderzoek/ onderzoeksprogrammas/structural-design/research/research-areasand-chairs/concrete-research-areas/3d-concrete-printing/. Accessed 21 Aug 2016.

[29] C. Gosselin, et al. Large-scale 3D printing of ultra-high performance concrete - a new processing route for architects and builders. Mater Des (2016) 100: 102-109. http://dx.doi.org/10.1016/j.matdes.2016.03.097

[30] A. Shahab et al. Smart dynamic casting or how to exploit the liquid to solid transition in cementitious materials. In: Proceedings CD of the 1st International Conference on Rheology and Processing of 
Construction Materials and of the 7th International Conference on Self Compacting Concrete, Paris (2014).

[31] E. Lloret et al. Complex concrete structures: Merging existing casting techniques with digital fabrication. Comput-Aided Des (2015) 60: 4049. http://dx.doi.org/10.1016/j.cad.2014.02.011

[32] L. Reiter, M. Palacios, T. Wangler, R.J. Flatt , Putting Concrete to Sleep and Waking It Up with Chemical Admixtures. Spec Publ (2015) 302: 145-154.

[33] L. Reiter, R. Kaessmann, T. Wangler, R.J. Flatt, Strategies to wake up sleeping concrete. In: Proceedings of International Conference on the Chemistry of Cement, Beijing (2015).

[34] M. Schultheiss et al., Feedback Control of Smart Dynamic Casting through Formwork Friction Measurements. In: Proceedings CD of the 8th International RILEM Symposium on Self-Compacting Concrete, Washington, DC (2016).

[35] L. Mettler, F. Wittel, R. Flatt, H. Hermann, Evolution of Strength and Failure of SCC During Early Hydration. Cem. Concr. Res. (2016) 89: 288-296. http://dx.doi.org/10.1016/j.cemconres.2016.09.004

[36] W.R. Schowalter, G. Christensen, Toward a rationalization of the slump test for fresh concrete: Comparisons of calculations and experiments. J Rheol (1998) 42: 865-870. http://dx.doi.org/10.1122/1.550905

[37] R.J. Flatt, P. Bowen, Yodel: A Yield Stress Model for Suspensions. J Am Ceram Soc (2006) 89: 1244-1256. http://dx.doi.org/10.1111/j.1551-2916.2005.00888.x

[38] G. Gelardi, R.J. Flatt, 11 - Working mechanisms of water reducers and superplasticizers. In: Sci. Technol. Concr. Admix. Woodhead Publishing, (2016) 257-278. http://dx.doi.org/10.1016/B978-0-08-100693-1.00011-4

[39] A. Perrot et al., Yield stress and bleeding of fresh cement pastes. Cem Concr Res (2012) 42: 937-944. http://dx.doi.org/10.1016/i.cemconres.2012.03.015

[40] N. Roussel, F. Cussigh, Distinct-layer casting of SCC: The mechanical consequences of thixotropy. Cem Concr Res (2008) 38: 624-632. http://dx.doi.org/10.1016/j.cemconres.2007.09.023 